\title{
Intravesical catheter knotting: an unusual complication of suprapubic catheterization
}

\author{
Murat Yiğiter, Ahmet Bedii Salman \\ Department of Pediatric Surgery, Ataturk University Faculty of Medicine, Erzurum, Turkey \\ E-mail:dryigiter@gmail.com \\ Received: 7th September 2015, Revised: 7th October 2015, Accepted: 17th November 2015
}

\begin{abstract}
SUMMARY: Yigiter M, Salman AB. Intravesicular catheter knotting: An unusual complication of suprapubic catheterization. Turk J Pediatr 2016; 58: 452-455.

Suprapubic catheterization is commonly used to drain urine temporarily from the bladder. Although it is a commonly performed procedure, it is not without complications. Many of these complications related to surgical technique. However, some unpredictable complications are related to the catheter itself. Intravesical catheter knotting is a very rare event and usually has been reported in feeding catheters used as an urethral catheter. We report a case of a suprapubic Cystofix catheter knot, removed by sustained traction. This complication was probably due to an excessive length of catheter having been inserted into the bladder, thus forming redundant loops that increased the risk of bending onto itself.
\end{abstract}

Key words: bladder, suprapubic catheter, knot, complication

Percutaneous suprapubic catheters are usually used for urinary diversion in lower urinary tract surgery in pediatric patients ${ }^{1}$. In hypospadias surgery, the advantages of suprapubic diversion are mainly a reduction of inflammatory reactions and infections in the lower urinary tract and prevention of occurrence of urethral fistula ${ }^{2}$. Hematuria, bladder wall edema, and bladder spasm are common catheter complications ${ }^{1}$. Intravesical catheter knotting is a very rare event and usually has been reported in feeding catheters used as a urethral catheter ${ }^{3-6}$. But a few case reports have been reported for Cystofix catheter knotting in the English literature. A diagnosis of intravesical catheter knotting is usually inconceivable and necessitates the knowledge about of this complication. To being aware of this complication and using proper placement technique can be minimized to the risk of knotting.

\section{Case Report}

A 1-year-old boy underwent surgery for proximal penile hypospadias. At the end of the operation, the bladder was distended artificially with $100 \mathrm{ml}$ saline using a 6-Fr Foley catheter. A 10-Fr suprapubic Cystofix catheter (Cystofix; Braun, Melsungen, Germany) was introduced percutaneously with a generous length extending within the bladder. The Foley catheter was left in place as a urethral stent. The urine was drained through the Foley and Cystofix catheters. Postoperatively, an anticholinergic agent (Oxybutynin Chloride, 0.3 $\mathrm{mg} / \mathrm{kg} / 24 \mathrm{~h}$ divided 2 doses) was prescribed to prevent possible bladder spasms due to the urinary catheters.

On the tenth postoperative day, the Foley catheter was removed, and the Cystofix catheter was clamped. About 4 hours later, the patient began to urinate from his neourethra. Since his urine stream was adequate, we decided to remove the Cystofix catheter. While it was being removed, resistance was felt at the end of the procedure; after sustained traction, the catheter was successfully removed without complication. The catheter was found knotted at its distal end (Figs. 1 and 2). After removal of the catheter, the child was discharged uneventfully.

\section{Discussion}

The use of catheters in the urinary tract is one of the most frequently performed practical procedures in children. Urethral catheterization 
is frequently used in critically ill children for obtaining urine culture and monitoring fluid balance. Less commonly it is also performed to relieve urinary retention, and for radiological evaluation of the lower genitourinary tract ${ }^{7}$.

In urologic practice, percutaneous suprapubic catheterization is frequently used for urinary diversion. In hypospadias surgery, the advantages of urinary diversion are mainly reducing inflammatory reactions that could decrease the urinary stream and allowing the neourethra to heal completely before contact with urine. There are few contraindications to its use, such as coagulation disorders ${ }^{2}$. Bladder distention is necessary for the catheter's safe placement. The complication rate of suprapubic cystostomy is very low and usually related to its placement or the presence of the catheter itself. Hematuria, edema, infection, and bladder

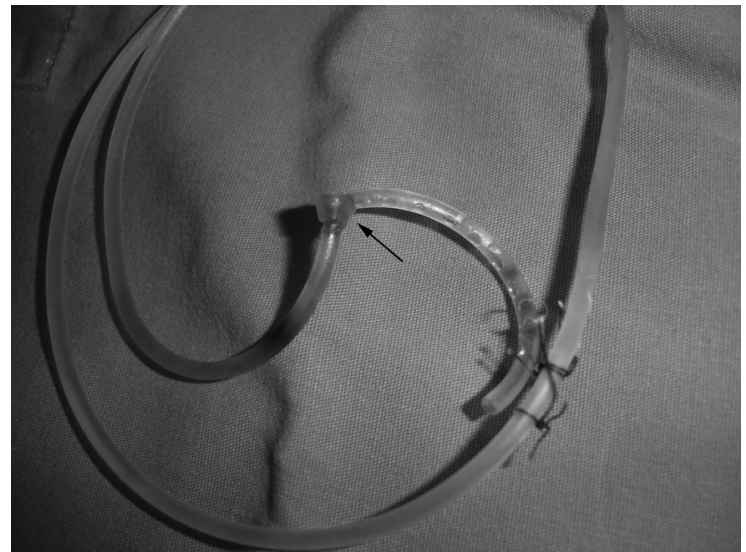

Fig. 1. The extracted Cystofix catheter, revealing the knot configuration (black arrow).

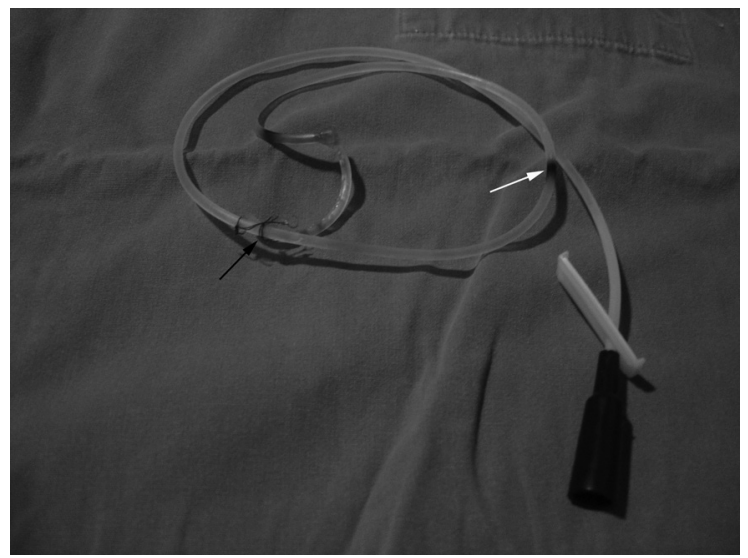

Fig. 2. Second proximal marking over the catheter (white arrow) and stabilization sutures, revealing the length of the catheter inside the bladder (black arrow). spasm are the most frequent complications ${ }^{1,2}$.

Although there have been reports of knotted urethral catheters, ${ }^{3-9}$ knotting of suprapubic catheters within the bladder has been reported in only a few cases $10-17$. In these reports, excessive length of introduced catheter, bladder spasms, overdistended bladder and catheter flexibility have been identified as factors responsible for the knotting of suprapubic catheters. In one report, detrusor contraction due to bladder irritation was suggested as the primary factor leading to folding, and an anticholinergic regimen was advised to prevent this complication ${ }^{10}$. However, the experience with our patient showed that an anticholinergic agent alone was not sufficient in preventing this complication. In fact, catheter knotting has also been reported in the heart, superior vena cava, pulmonary artery and epidural space ${ }^{18-21}$. Therefore, we think that catheter knotting is a more complex event and is not only due to bladder spasm.

Knotting within the bladder with suprapubic catheterization is most likely due to the length of the curling end of the catheter. Excessive length of the inserted catheter and low bladder capacity increase the number of curls and cause looping and folding onto the catheter itself, particularly when low bladder volume is maintained via continuous drainage. Advancement of the urinary catheter could be discontinued when it starts draining the bladder. Whereas, this is not true with the supra pubic catheter because sufficient length has to be inserted into the bladder so that residual volume is kept to a minimum. In addition, having two catheters inside the bladder may increase the chances of intra-vesical knotting, especially when using the improper catheters. Ideally, the Foley's catheter should be used in the urethral catheterization of children $22-23$. However, the infant feeding tube is still a suitable alternative, especially in the developing countries where pediatric size Foley's catheters may not be readily available 24 . The knotting of a cystostomy catheter over a Foley catheter has been reported previously5-14-15. But, only two case reports revealed a Cystofix catheter knotting over itself even though it was inserted with a Foley catheter ${ }^{13-17}$. In this very rare situation, it may be speculated that inflated balloon cuffing of the Foley catheter may create 
a supportive surface facilitated bending onto catheter itself. To eliminate redundant loops within in the bladder, despite the desire to fully drain the bladder, our advice is to advance the catheter only up to the minimum distance required to obtain urine flow. If two catheters will be inserted within the bladder simultaneously, as a new proposal, not inflating the balloon cuffing of the Foley catheter may help to prevent this complication.

The existence of a knotted catheter is usually suspected when the catheter cannot be withdrawn or when urine flow from the catheter has ceased ${ }^{11}$. As in our patient; ongoing drainage from the catheter indicates an open lumen. Thus, a slight knot or folding of the catheter can be changed into a true knot inside the bladder when the catheter is pulled out ${ }^{10}$.

A number of techniques have been described for removal of knotted catheter including sustained traction under anesthesia, untying the knot using a guide-wire through the catheter under fluoroscopy, endoscopic removal, and surgical extraction with suprapubic percutaneous cystotomy ${ }^{11}$.

Passage of an internal guide wire under fluoroscopy is suggested when knots are loose or formed by large loops. A wire guide is introduced through the catheter and the pressure straightens the knot by increasing catheter rigidity. However, external guide wire technique can be used to undo the tightest knots comprised one loop by using the pig tail end of the external guide. When the above methods are inadequate, the knotted catheter can be extracted with sustained traction. The technique uses a continuous and progressive traction of the catheter to reduce the knot size, which permits the catheter to exit through the skin orifice. The knotted suprapubic catheter could be removed under general anesthesia via endoscopic or open surgery. Surgical techniques should be used when the nonsurgical methods have failed. The knot is cut with endoscopic scissors, and foreign body forceps extract the knotted fragment. Open surgery removes the knotted catheter through a minimal cystotomy. This technique should be used for large or calcified knots ${ }^{17}$.
However, manual extraction of the suprapubic catheter was an acceptable alternative ${ }^{11}$. We were able to remove the knotted catheter with minimal effort and sustained traction without any complications.

\section{REFERENCES}

1. Ring KS, Hensle TW. Urinary diversion. In: Kelalis PP, King LR, Belman AB, eds. Clinical Pediatric Urology. Philadelphia, PA: WB Saunders; 1992: 865-903.

2. Hadidi AT. Principles of hypospadias surgery. In: Hadidi AT, Azmy AAF, eds. Hypospadias Surgery: An Illustrated Guide. Berlin: Springer; 2004: 99-105.

3. Turner TW. Intravesical catheter knotting: an uncommon complication of urinary catheterization. Pediatr Emerg Care 2004; 20: 115-117.

4. Mayer E, Ankem MK, Hartanto VH, Barone JG. Management of urethral catheter knot in a neonate. Can J Urol 2002; 9: 1649-1650.

5. Raveenthiran V. Spontaneous knotting of urinary catheters: clinical and experimental observations. Urol Int 2006; 77: 317-321.

6. Foster H, Ritchey M, Bloom D. Adventitious knots in urethral catheters: report of 5 cases. J Urol 1992; 148: 1496-1498.

7. Arena B, McGillivray D, Dougherty G. Urethral catheter knotting: be aware and minimize the risk. CJEM 2002; 4: 108-110.

8. Sambrook AJ, Todd A. Untangling of knotted urethral catheters. Pediatr Radiol 2007; 37: 380-383.

9. Sujijantararat P. Intravesical knotting of a feeding tube used as a urinary catheter. J Med Assoc Thai 2007; 90: 1231-1233.

10. Arda IS, Ozyaylali I. An unusual complication of suprapubic catheterization with Cystofix: catheter knotting within the bladder. Int J Urol 2001; 8: 188189.

11. Gardikis S, Soultanidis C, Deftereos S, et al. Suprapubic catheter knotting: an unusual complication. Int Urol Nephrol 2004; 36: 537-539.

12. Thorfinn J, Tarpila E. Intravesical self-tying knots in suprapubic catheters: a report of two cases. Scand J Urol Nephrol 2008; 42: 86-87.

13. Farook SA, Kariholu U, Kousidis G, et al. Not to knot a catheter. Case report of the knotting of a suprapubic catheter. TSW Urology 2007; 7: 1004-1006.

14. Villeta M, Vitagliano G, Castillo O. A rare complication associated to a suprapubic cystostomy: catheter knotting. Arch Esp Urol 2007; 60: 95-96.

15. Polychronidis A, Kantartzi K, Touloupidis S, Nikolaidis I, Simopoulos C. A true knot in a suprapubic catheter around a urethral catheter: a rare complication. J Urol 2001; 165(6 Pt 1): 2001.

16. Mir M, Bali B, Hamza W. Spontaneous knotting of suprapubic catheter-A rare complication and a rare cause of retained suprapubic catheter. The Internet Journal of Urology 2012; 9: 1-3 
17. Romero Pérez P, Lapuerta Torres FE, Amat Cecilia $\mathrm{M}$, et al. Suprapubic cystostomy catheter knotting. Presentation of the first national case and review of the literature. Arch Esp Urol 2013; 66: 221-230.

18. Ahmed H, Kaufman D, Zenilman ME. A knot in the heart. Am Surg 2008; 74: 235-236.

19. Akhtar MI, Hamid M, Khan FH, et al. Pulmonary artery catheter knotting in a coronary artery bypass surgery patient. J Pak Med Assoc 2007; 57: 519-521.

20. Arnaoutoglou HM, Tzimas PG, Papadopoulos GS. Knotting of an epidural catheter: a rare complication. Acta Anaesthesiol Belg 2007; 58: 55-57.
21. Hatim A, Belyamani L, Drissi M, et al. Knotting catheter in the superior vena cava: rare complication of SwanGanz. Ann Fr Anesth Reanim 2008; 27: 761-762.

22. Anbu AT. Urethral catheter knotting in preterm neonates. Indian Pediatr 2004; 41: 631-632.

23. Carlson D, Mowery BD. Standards to prevent complications of urinary catheterization in children: should and should-knots. J Soc Pediatr Nurs 1997; 2: $37-41$.

24. Gnanaraj J, Gnanaraj L. The infant feeding tube: a boon to the rural urologist. Trop Doct 1996; 26: 191. 